\title{
ENERGY EFFICIENT ELECTRONICS COOLING PROJECT
}

FINAL TECHNICAL REPORT

DOE AWARD NUMBER: O9EE0000412

11:2009-11:2011

STEVE O'SHAUGHNESSEY

260-748-6082

SOSHAUGHNESSEY@PARKER.COM

TIM LOUVAR

260-748-6155

TIM.LOUVAR@PARKER.COM

MIKE TRUMBOWER

260-748-6173

MTRUMBOWER@PARKER.COM

JESSICA HUNNICUTT

260-748-6062

JESSICA.HUNNICUTT@PARKER.COM

PARKER HANNIFIN CORPORATION

PRECISION COOLING BUSINESS UNIT

10801 ROSE AVENUE

NEW HAVEN, IN 46774

SUBMITTED: 2/17/2012 


\section{ACKNOWLEDGEMENT}

This report is based upon the work supported by the U.S. Department of Energy Award No. 09EE0000412

\section{DISCLAIMER}

Any findings, opinions, and conclusions or recommendations expressed in this report are those of the Parker Hannifin Precision Cooling Business Unit and do not necessarily reflect the views of the Department of Energy.

\section{DOCUMENT AVAILABILITY}

Reports are available free via the U.S. Department of Energy (DOE) Information Bridge Website: http://www.osti.gov/bridge

Reports are available to DOE employees, DOE contractors, Energy Technology Data Exchange (ETDE) representatives, and Informational Nuclear Information System (INIS) representatives from the following source:

Office of Scientific and Technical Information

P.O. Box 62

Oak Ridge, TN 37831

Tel: (865) 576-8401

FAX: (865) 576-5728

E-mail: reports@osti.gov

Website: http://www.osti.gov/contract.html 


\section{TABLE OF CONTENTS}

ACRONYMS

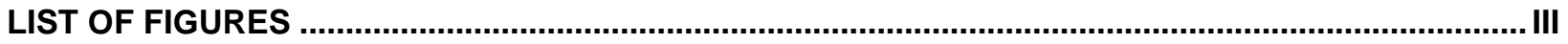

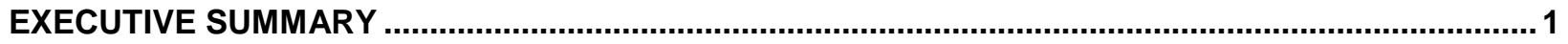

INTRODUCTION

BACKGROUND

Converter Module

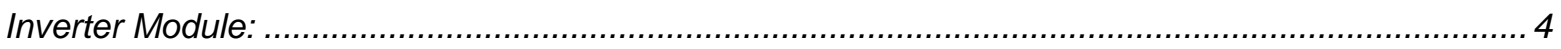

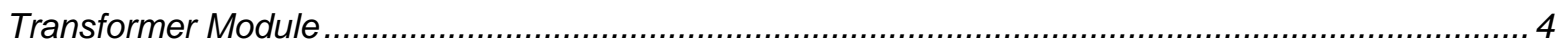

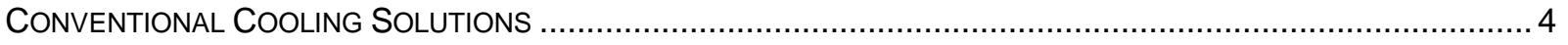

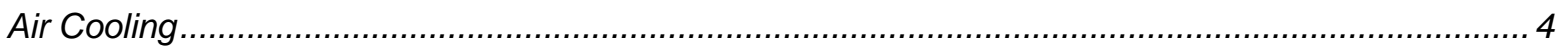

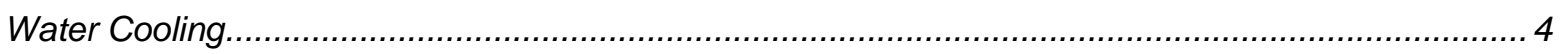

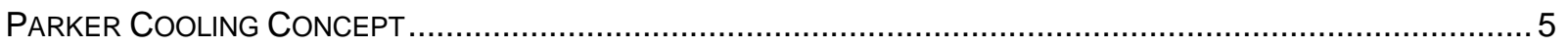

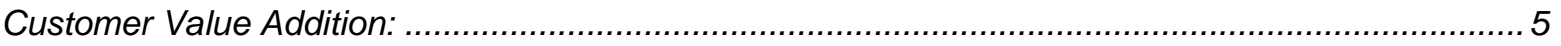

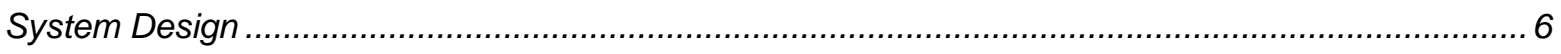

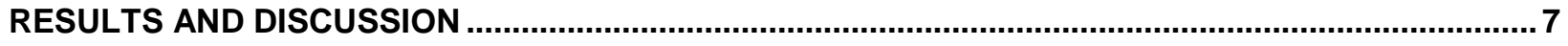

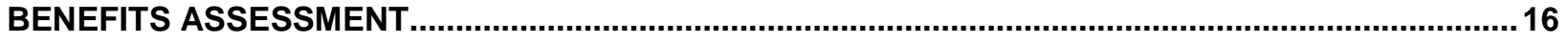

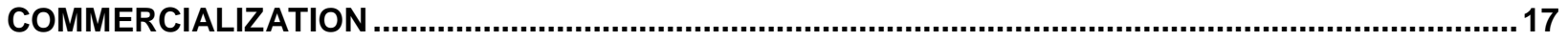

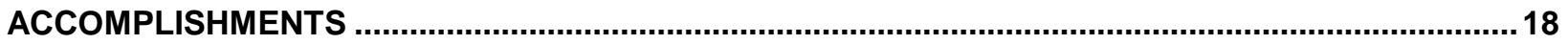

CONCLUSIONS

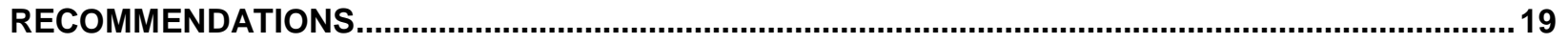

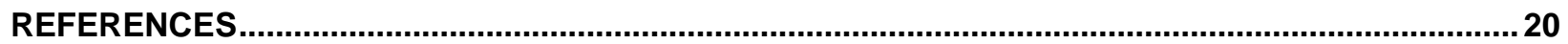




$\begin{array}{ll}\text { AC } & \text { Alternating Circuit } \\ \text { DC } & \text { Direct Current } \\ \text { DOE } & \text { United States Department of Energy } \\ \text { gal } & \text { Gallons } \\ \text { gpm } & \text { Gallons per minute } \\ \text { IEC } & \text { International Electro-technical Commission } \\ \text { IGBT } & \text { Insulated-Gate Bipolar Transistor } \\ \text { mm } & \text { Millimeters } \\ \text { MVA } & \text { Megavolt Ampere } \\ \text { PDA } & \text { Personal Digital Assistant } \\ \text { VDF } & \text { Vaporizable Dielectric Fluid }\end{array}$

\section{LIST OF FIGURES}

Figure 1 - Transformer Cooling Simulation

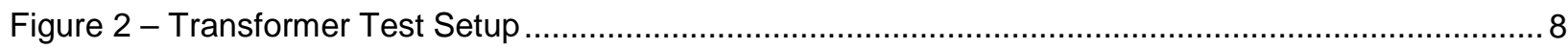

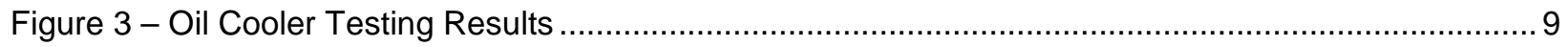

Figure 4 - Computer Simulation of Air-Cooled Performance …..................................................... 10

Figure 5 - Rendered Design of Parker Cooling Solution for Torodial Transformer ............................... 11

Figure 6 - Construction of Enclosure Box with Parker Cooling Lines Installed ...................................... 11

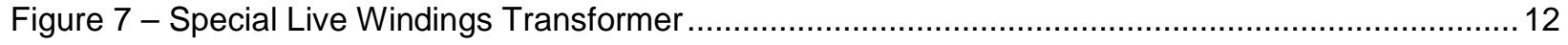

Figure 8 - Test Setup of Living Winding Transformer Parker Cooled System ................................... 13

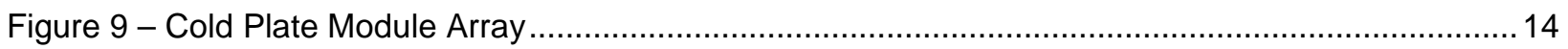

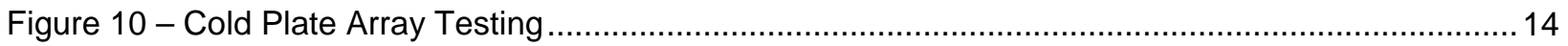

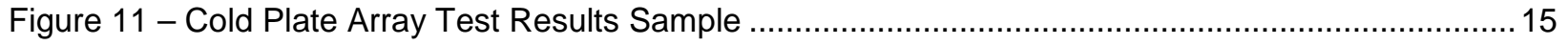

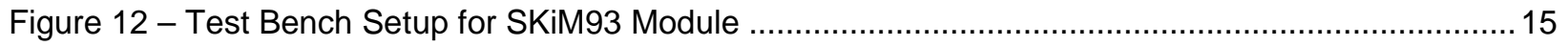

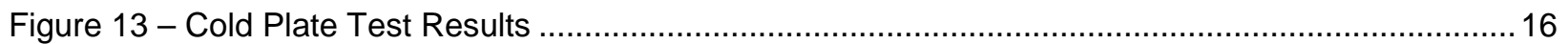


Parker Precision Cooling Business Unit was awarded a Department of Energy grant (DE-EE0000412) to support the DOE - ITP goal of reducing industrial energy intensity and GHG emissions. The project proposed by Precision Cooling was to accelerate the development of a cooling technology for high heat generating electronics components. These components are specifically related to power electronics found in power drives focused on the inverter, converter and transformer modules. The proposed cooling system was expected to simultaneously remove heat from all three of the major modules listed above, while remaining dielectric under all operating conditions.

Development of the cooling system to meet specific customer's requirements and constraints not only required a robust system design, but also new components to support long system functionality. Components requiring further development and testing during this project included pumps, fluid couplings, cold plates and condensers. All four of these major categories of components are required in every Precision Cooling system. Not only was design a key area of focus, but the process for manufacturing these components had to be determined and proven through the system development.

The Precision Cooling Business Unit identified a few key projects to be the focus of the DOE grant. The first key project was to develop a cooling system for low voltage industrial drives used for power conversion and inversion. These systems utilize insulated-gate bipolar transistors (IGBTs) to complete switching at very high frequencies in a small amount of space. The use of IGBTs results in relatively high amounts of heat needing to be dissipated, or removed, from the electrical device efficiently. Water and air have been used for cooling these devices, but require the device to be de-rated at elevated ambient temperatures, because they do not have the thermal capacity of Parker's Vaporizable Dielectric Fluid (VDF) cooling system.

In order to show the value of the Parker cooling solution, comparison testing had to be conducted using different types of IGBTs. The first IGBT tested was the Eupec FZ1200R17KF6CB2. The testing of this IGBT showed results that indicated the VDF, or two-phased, cooling solution developed by Parker resulted in a thermal resistance that is roughly half of a water system. Another IGBT tested was a baseplate-less module by Semikron called the SKiM93 module. This unique module attaches the electronic circuit board directly against the cold plate using a spring loaded mounting system instead of being mounted to an intermediary copper plate, thus reducing the thermal resistance between the IGBT dies and the cooling fluid. The results of the comparison testing between air, water and VDF of this IGBT showed that Parker's two-phased cooling resulted in 50\% lower thermal resistance at $80 \%$ less flow rate and $10 \%$ less thermal resistance at $96 \%$ less flow rate and even enabled performance at conditions that water and air could not effectively cool.

By reducing the thermal resistance, the cooling system does not require as much fluid flow resulting in lower pump power required, smaller plumbing, and improved performance by the electronics. All of these benefits individually result in reduced energy consumption during the manufacture of the components and cooling system operation. When the benefits are combined, it enables the power drive manufacturer to run the electronics without de-rating at elevated ambient conditions resulting in improved performance and a reduction in the number of components required. This also supports a reduction in GHG emissions since less power is required for the complete system (including the cooling system).

The development and performance of these systems is not possible without the development work that went into the design and manufacturing of the cold plates, tubing, pumps and condensers. These components have to be specifically designed to support effective system operation to provide the 
performance improvements demonstrated in the testing discussed above. These components were also used in support of the transformer cooling projects that were completed as part of the grant.

Three different methods for cooling transformers via two-phased refrigerant were explored in detail. The three methods were:

- Submerging a transformer in mineral oil and pumping the mineral oil through an oil to refrigerant heat exchanger to extract the heat

- Potting a copper coil around a transformer and pumping refrigerant through the copper coil to extract the heat

- Use a specially-designed transformer with hollow tubes as the primary and secondary windings and pumping refrigerant through the tubes to extract the heat

The development of the submerged transformer cooling system did not require a significant change to the transformer design. This enables customers to utilize an "off the shelf" transformer and get the advantages of the two-phased cooling without significant integration work. The system design and test proved successful, with the refrigerant able to remove the required heat load and hold the mineral oil within a maximum operating temperature specified by the customer. The success of this cooling system has enabled Parker to launch a production cooling system. The disadvantage of this cooling is that there is an extra thermal resistance of the heat exchanger, so the windings will run hotter than the refrigerant temperature. For some customers, this increased temperature will not enable the transformer to operate in all conditions, so it is not an acceptable solution.

To support customers that need improved performance, Precision Cooling proceeded to pot a copper coil around a transformer and use refrigerant to cool. The specific application required that three toroidal transformers be packaged in an IP66 rated enclosure. The rating requirement of the enclosure requires that it be sealed from the outside ambient making it very difficult to effectively cool using air. The resulting thermal analysis indicated that the transformer core temperature would be $221 \mathrm{deg}$. C., which exceeds the wire insulation temperature limit. By utilizing the copper tube coil and VDF cooling, the toroidal transformer outer surface temperature, during testing, was found to not exceed $85^{\circ} \mathrm{C}$.

The final option for transformer cooling requires a fully integrated copper coil that not only transports the refrigerant for cooling, but also carries a live voltage. Therefore, dielectric hose was needed to connect the windings to the rest of the cooling system. Liquid refrigerant could then be pumped into each winding as a liquid, where it then partially boiled as it absorbed heat and was then pumped to a condenser to reject that heat. Testing showed that the winding temperatures were maintained at nearly the same temperature as the refrigerant. This lower temperature operation results in improved efficiency for the transformer, resulting in fewer electrical losses and less power generation required for system functionality.

The performance improvements illustrated above for inverters and converters utilizing refrigerant cooled IGBTs and transformers, taking advantage of the same technology, has enabled Parker to launch multiple industrial products into the market. Parker is continuing to develop new products as Precision Cooling expands into new markets including mobile/traction products, data center cooling, and the medical equipment industry. The ability to expand into these new markets can be directly attributed to the products that were developed and commercialized using a combination of Parker funds and the Department of Energy grant. 


\section{INTRODUCTION}

The following report includes a summary of the work performed as initially stated by the "VDF Multisystem Cooling Technology Development" DE-EE0000412-Energy Efficient Project Proposal. Parker Precision Cooling has demonstrated and continues to research how to efficiently cool high heat generating electronic components for high power electronics. The donated DOE grant was used specifically for the opportunity to research, develop, and commercialize cooling systems for converter modules for converting $A C$ power to DC power, inverter modules for converting DC power to AC power, and the transformer module for changing output voltage. It is essential to the thermal management of these components to preserve their life expectance, performance, and reliability.

Current thermal management solutions include water cooling systems or forced fan convection (air cooling). Parker's dielectric cooling system removes the excessive and harmful heat from the sensitive components to improve their safety and efficiency. The following sections describe the work completed to construct, test, and verify Parker Precision Cooling system(s) and that these can cool converter modules, inverter modules, and transformer modules.

\section{BACKGROUND}

Power electronics systems are found in a wide range of electrical and electronic equipment. These range from smart phones and PDAs, which require only a few Watts of power, to large industrial power systems, which handle several hundred Megawatts of electric power. Most of these systems can be categorized into four main categories:

\section{TO DC CONVERSION:}

This power conversion includes mostly portable applications that run on a battery. Examples include a laptop computers and cellular phones.

\section{AC TO DC CONVERSION (RECTIFICATION):}

Rectification is the process of converting the AC power to DC power. Applications of AC to DC power conversion include battery chargers and DC motors that draw current from the AC line.

DC TO AC CONVERSION (INVERSION):

Inversion is the opposite of rectification as it converts the DC power to AC power. The inverters are used in wind turbines, backup power systems.

\section{AC TO AC CONVERSION:}

The process of $A C$ to $A C$ power conversion involves either changing the output voltage, achieved by a transformer, or through a much more complex frequency conversion.

Of the power conversion processes described above, rectification, inversion, and $A C$ to $A C$ are the primary focuses of the DOE grant, as these generate the highest amount of cooling loads. The power electronics drives commonly consist of the following modules described below that use these conversion processes. Please note that the relative heat generation values described is based on a standard power drive. For different configurations, these distributions may be different. 
CONVERTER MODULE

A converter module converts AC power to DC power. Important electronic components examples include diodes, thyristors, and silicon-controlled rectifiers. The heat generated in these devices are lower compared to other modules and is approximated as $20 \%$ heat generation of the complete system.

INVERTER MODULE:

The inverter module converts DC power to AC power. The most important electronic component of this module is the insulated-gate bipolar transistor (IGBT) which generates a lot of heat due to switching. The heat generated by the IGBTs is high and accounts for roughly $40 \%$ of the total system heat generation.

TRANSFORMER MODULE

An electric transformer is usually associated with increasing or decreasing AC voltage. It has primary and secondary windings through which electric current passes. Induction heating of the coils causes heat generation in the transformer which accounts for roughly $40 \%$ heat generation of the entire power system.

\section{CONVENTIONAL COOLING SOLUTIONS}

Most of the current industrial power drive systems use either air cooling or single-phase water cooling solutions for thermal management of the drives. These two cooling techniques are briefly described in the following sections.

\section{AIR COOLING}

This is the simplest method for transporting heat away from the electronics. This is accomplished by blowing air directly across the heat-generating electronic(s). The heat transfer area is usually enhanced by using finned heat sinks. This technique, though simple, suffers from the fact that thermal conductivity of the air is poor and hence limits the amount of heat carried away by it. The limitation of heat being removed results in de-rating of the electronics components, thereby forcing the use of more components (which results in increase in cost and space) for achieving the performance.

\section{WATER COOLING}

This cooling technique employs use of single-phase liquid water for removing heat from the electronics components. Excellent thermodynamic properties of water and its availability are the biggest advantages to this cooling process; however, water cooling suffers from the following drawbacks:

- $\quad$ Liquid water is a conducting fluid and runs a risk of damaging the electronics if spilled or leaked.

- Single-phase cooling has proven to be less effective than a two-phase cooling. Thus more electronic components are required for generating the required power.

- Single-phase water requires higher flow rates. Hence a larger water pump and piping is necessary, which adds weight to the overall cooling system. 


\section{PARKER COOLING CONCEPT}

In its simplest form, the Vaporizable Dielectric Fluid (VDF) system can be thought of as an externally pumped heat pipe thermal management system. Heat pipes have been used for many years for their effectiveness in handling high heat fluxes with very low temperature rise, but are difficult to implement due to the physical shape and size limitations. Since the VDF system uses a fluid pump and does not rely on capillary pumping, like a heat pipe, the system can be easily integrated with most any current power electronics design. The pumped fluid follows a cycle similar to the Rankin cycle as heat is absorbed in an evaporator and then transferred back to ambient through a condenser. The fluid loop can contain parallel and series branches for the evaporators and since the heat generated in each of these electronics modules can be different, the use of flow restrictors or a flow balancing devices can be used in each of the parallel paths. The devices provide a balanced flow of liquid in the circuit avoiding the danger of a dry-out condition due to lack of sufficient liquid flow rate in any single circuit.

CUSTOMER VALUE ADDITION:

It is believed that the Parker cooling solution has potential for a huge value addition to the customer. Following are some important prospects:

SINGLE COOLING SOLUTION:

The customer can potentially cool the entire power electronic system with one cooling system.

WATERLESS SOLUTION:

While water is one of the best coolants, it is also one of the most dangerous. A small leak or spill of water can potentially destroy the components. The Parker solution completely eliminates water from the equation, replacing it with an electronics-friendly dielectric refrigerant.

\section{SMALLER SIZE:}

As discussed earlier, the refrigerant-cooled IGBTs and diodes can be pushed harder and therefore can run at their true potential (de-rating required in case of water-cooled drives). Hence, fewer components are required by the system to achieve the required power rating. This results in a significant footprint reduction of the cooling system than air or water solutions. (Roughly $66 \%$ compared to air cooled and $33 \%$ compared to water cooled drives). Fewer components also results in less energy intensity by the industrial company to help reduce GHG emissions from power companies.

\section{SMALLER TUBING:}

Since the volumetric flow rate required by the Parker cooling system is less than $1 / 3$ of that of the water cooling system, the size of tubing is significantly reduced.

\section{SMALLER PUMPS:}

The lower flow rate also equates to a smaller pump. The Parker cooling system uses a smaller, dielectric fluid pumps versus a large pump used in water cooling systems. The smaller pumps result in less energy intensity by the end customer reducing their operating expenses. 
NO VAPOR LOCK:

Specifically for the transformer coil, using two phase-refrigerant eliminates the possibility of vapor (or air) lock. This phenomenon is especially seen in water-cooled transformers and can result in hardware failure.

SIMPLE SYSTEM:

The refrigerant cooled system contains fewer components and completely eliminates the need for deionization tanks, degassers, strainers, etc.

SYSTEM DESIGN

The Parker cooling system consists of the following major components:

COLD PLATES:

Parker heat sinks (commonly referred to as cold plates) act as the heat exchanger for various power electronics by conduction. A thermal interface material is placed between the heat emitting electronics and the heat sink for lower thermal resistance. Refrigerant enters the micro-channel cold plate with low initial energy, absorbs heat from the electronics and leaves with high thermal energy. The cold plates can be fabricated with various materials and configurations. Many resources have been dedicated at our facility in production and process development of the heat sinks.

HOLLOW TRANSFORMER COIL:

A Parker cooling system can cool an electrical transformer by passing liquid refrigerant through a hollow coil of the primary and secondary windings. As the refrigerant flows through the coil, it absorbs the generated heat and leaves as a two-phase mixture. Compared to the external cooling of the IGBTs and other power electronics components, the transformer module is cooled internally. This produces a lower thermal resistance.

\section{CONDENSER:}

The system condenser is where the heat absorbed from the electronics is rejected to the ambient. Two kinds of condenser designs are possible. An air-cooled condenser rejects heat directly to ambient by blowing air across the surface of the condenser. Depending on the overall heat load, the coil size of the condenser can be large. The second type of condenser is the water-cooled condenser in which a coolant (water + ethylene glycol) carries heat away from the condenser and rejects it to the ambient using a separate radiator (similar to the radiator in the vehicles). These two options allow Parker cooling systems to be customized to the customer' needs.

\section{DIELECTRIC PUMP:}

The liquid pump pressurizes the liquid refrigerant and ensures a constant flow rate of the refrigerant in the system. Depending on the cooling requirements of various power electronics, two or more liquid pumps can be used for achieving the required pressure and flow rate(s). Parker has designed and implemented advance testing of these liquid pumps for cooling a variety of applications to provide quality and reliability of the cooling systems.

FLOW RESTRICTORS: 
Flow restrictors are necessary for avoiding dry-out conditions in either of the modules due to lack of sufficient liquid flow rates. Various designs of flow restrictors are considered, the simplest being a fixed area orifice. A spring-operated variable area flow restrictor is designed and is undergoing testing at the Parker New Haven facility.

\section{ISOLATION BLOCKS/DIELECTRIC HOSES:}

Power drive systems run live current through their modules and these modules must be electrically isolated from each other and also from the cooling cycle. This is necessary not only for a steady operation of the drive, but also for the safety of personnel operating the drive.

\section{TUBING:}

Tubing plays an important role in the system design as it governs the system's pressure drop. Parker New Haven facility has full tube bending, forming and brazing capabilities. Copper tubing is preferred because of its system friendliness: no corrosion issues, easy to cut, form and bend, easier to braze or solder etc. In certain scenarios in which non-metallic tubing is necessary to electrically isolate an electronic component, flexible hoses made of rubber or polymers can be used instead.

\section{RESULTS AND DISCUSSION}

\section{TRANSFORMER COOLING}

Three different methods for cooling transformers via two-phase refrigerant were explored in detail. The three methods were:

- Submerging a transformer in mineral oil and pumping the mineral oil through an oil to refrigerant heat exchanger to extract the heat

- Potting a copper coil around a transformer and pumping refrigerant through the copper coil to extract the heat

- Use a specially-designed transformer with hollow tubes as the primary and secondary windings and pumping refrigerant through the tubes to extract the heat

For the first method, an electrical system consisting of a transformer submerged in mineral oil was selected. A picture of the system can be shown in Figure 1. 


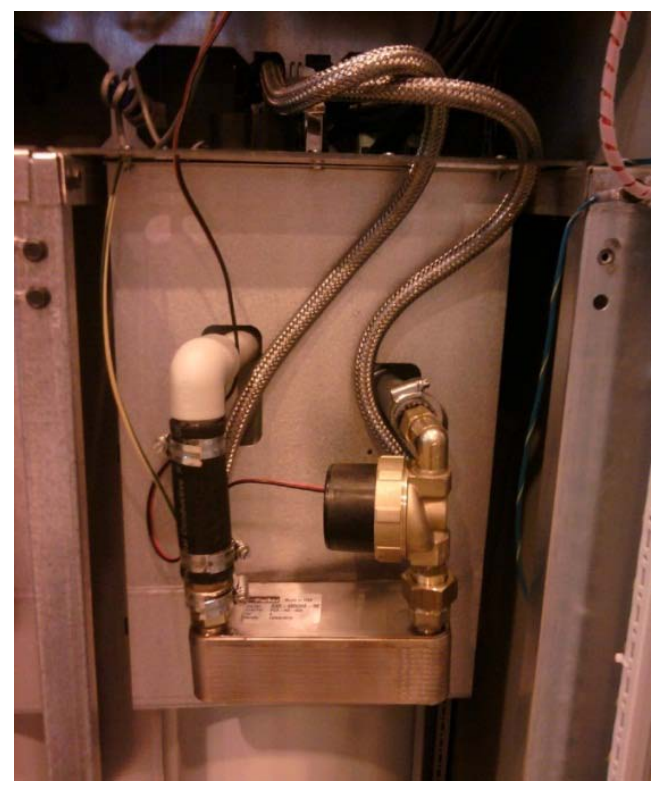

Figure 1 - Transformer Cooling Simulation

The transformer is located within the PVC cylinder and is submerged with an electrical grade mineral oil. The oil is pumped from the cylinder via a pump located just before the heat exchanger, then circulated through the heat exchanger and back into the PVC cylinder. Refrigerant is pumped into the heat exchanger in a liquid state via a flexible stainless hose, then partially boils as it extracts heat from the mineral oil, then the two-phase refrigerant is routed back to the rest of the system via another flexible stainless hose.

The system was simulated at Parker's facility by replacing the transformer with a tank filled with mineral oil with a submersion heater located in the fluid. This allows for the ability to accurately produce the intended amount of heat without introducing the high voltage and high power load banks. A picture of the test setup can be shown in Figure 2.

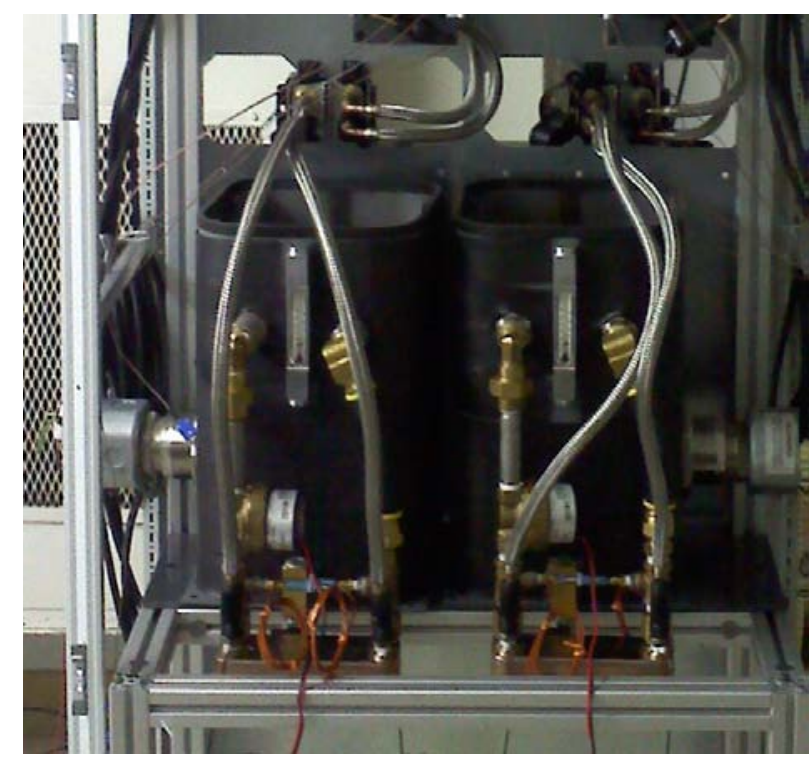

Figure 2 - Transformer Test Setup 
Testing was performed at several flow rates and with three different heat exchangers with different numbers of plates. The results can be seen below in Figure 3.

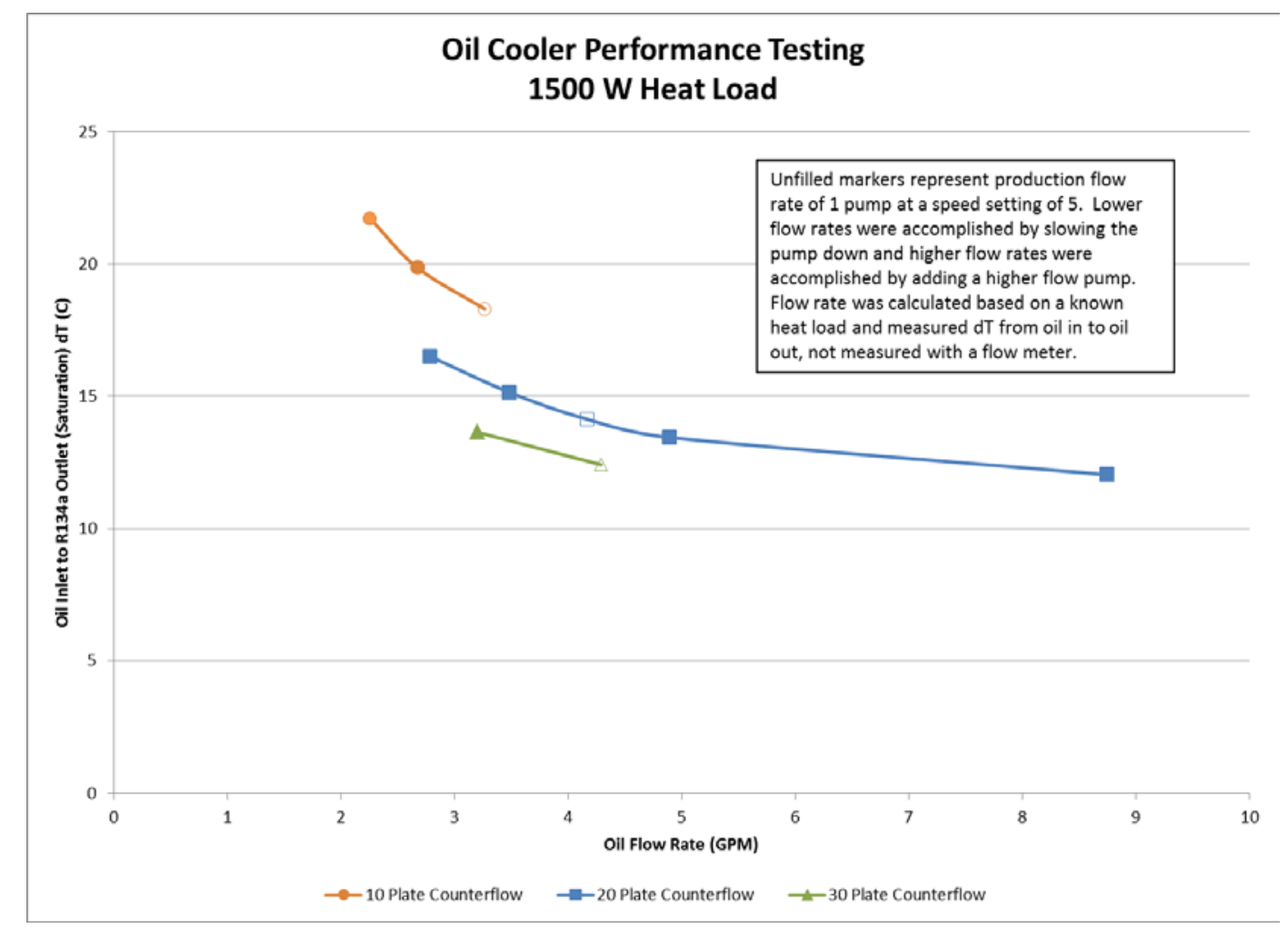

Figure 3 - Oil Cooler Testing Results

Testing demonstrated that the refrigerant was able to remove the required heat load and hold the mineral oil within a maximum operating temperature specified by the customer. The customer needed the refrigerant-to-oil delta- $T$ to be less than $15 \mathrm{C}$ at a heat load of $1.5 \mathrm{~kW}$. It was assumed that the transformer windings would remain approximately the same temperature as the mineral oil since there is a sufficient amount of surface area between the windings and the fluid, therefore a low heat flux. Adding more plates reduces the temperature differential between the refrigerant and the oil, as did increasing the oil flow rate, although both had diminishing returns. The final solution was to use a 20 plate heat exchanger with a mineral oil flow rate of about $4 \mathrm{gpm}$. This solution met the design specifications while meeting other constraints such as size and cost.

This method of removing heat from a transformer via an intermediate fluid proved to be successful and Parker has launched a production cooling system utilizing this approach. The advantage of the approach is that there are very little changes needed to the transformer design, if it is already designed to be submerged in a fluid. The disadvantage is that there is an extra thermal resistance of the heat exchanger, so the windings will run hotter than the refrigerant temperature. This differential depends on the heat exchanger design and the flow rate of the transformer cooling fluid.

For the second method for cooling a transformer via potted tubing around the transformer, a different electrical system was analyzed and tested. As part of this cooling technology development, Parker worked on a project where cooling was required for 3 toroidal transformers placed in an air-tight enclosure. The toroidal transformers were approximately 9 inches in diameter and 3 inches in height, each rated for $11 \mathrm{~kW}$ of power conversion. Typically, toroidal transformers are rated to $99 \%$ efficiency 
which means the transformers will dissipate up to 110 watts of heat each. The 3 toroidal transformers were part of a power converter package used on mobile platforms. The customer required an IP66 level of protection for the power converter package, which meant there would not be sufficient cooling from just internal air circulation. [1] The transformers utilize a UL Class H (180 deg. C.) wire insulation system. [2] Under minimal air circulation (i.e. natural convection or a small fan), the transformer has a temperature rise of $62 \mathrm{deg}$. $\mathrm{C}$. from the ambient air temperature to the transformer surface. The windings core temperature would have approximately a $20 \mathrm{deg}$. C. rise from the surface temperature. A thermal simulation was done to investigate if natural convection with air could be sufficient to cool the 3 toroidal transformers. As seen in Figure 4, transformer core temperature was predicted to be 221 deg. C., which exceeds the wire insulation temperature limit.

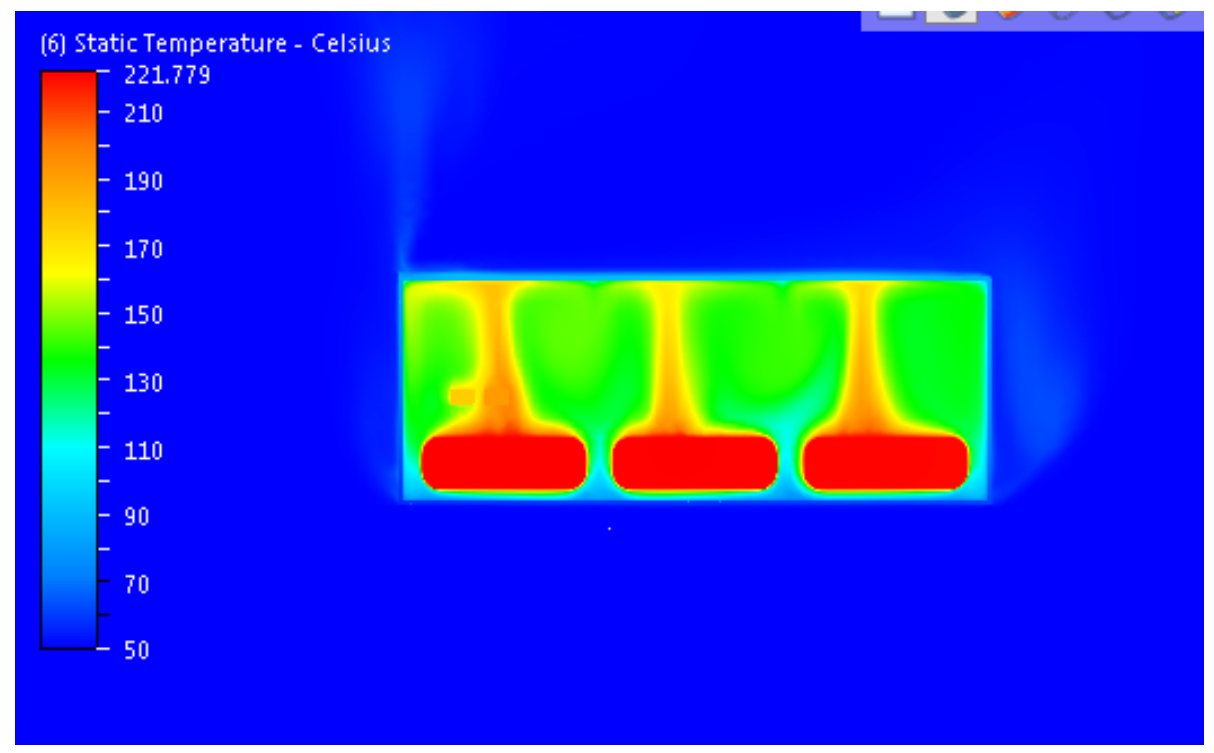

Figure 4 - Computer Simulation of Air-Cooled Performance

Since the Parker cooling system was previously implemented in a power converter package of IGBTs in an inverter module, it was decided to use the 2-phase refrigerant for cooling of the transformers as well. A design was laid out with copper tubing wrapped around the outside of the toroid transformer. To provide thermal contact from the outside surface of the transformer to the copper coil, the copper tubing is potted in a thermally-conductive epoxy potting compound. The render in Figure 5 shows the design: 


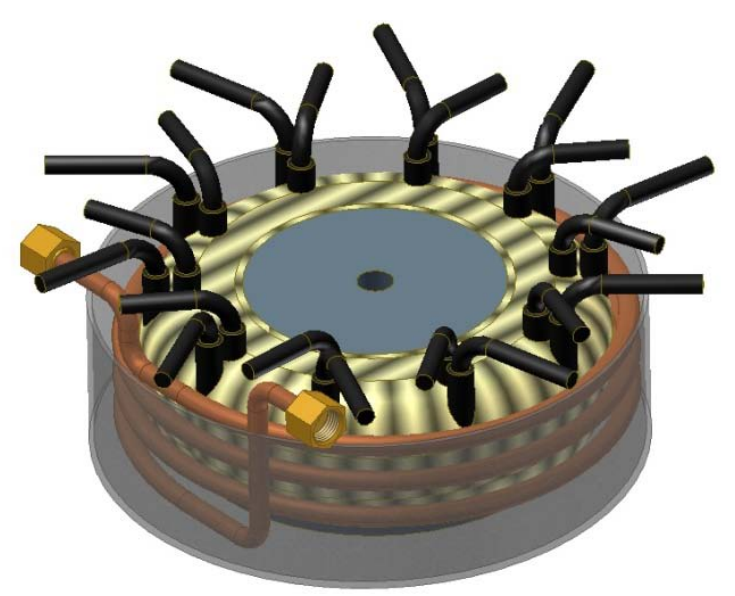

Figure 5 - Rendered Design of Parker Cooling Solution for Toroidal Transformer

Figure 6, below, shows transformers with cooling lines placed in the enclosure box:

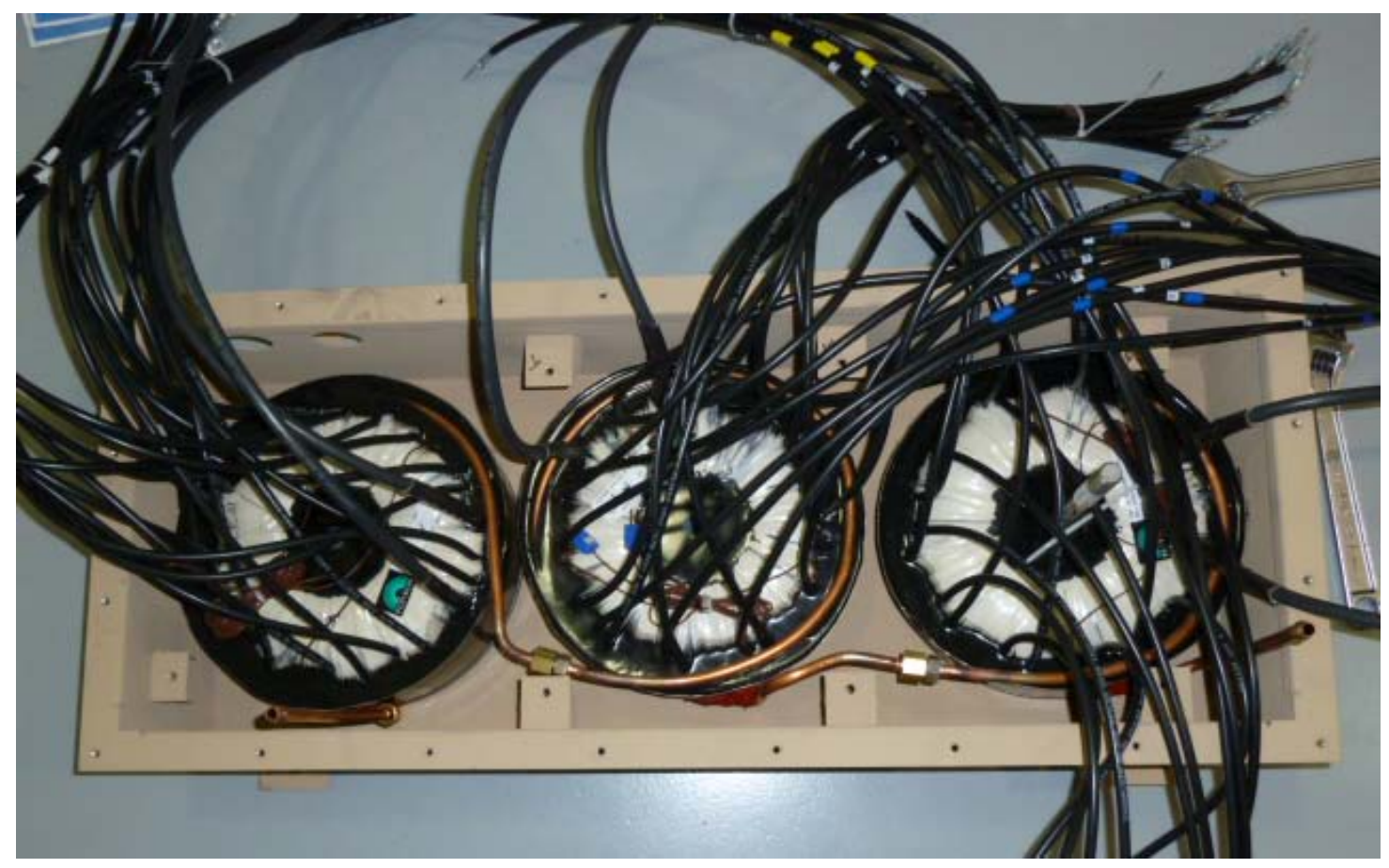

Figure 6 - Construction of Enclosure Box with Parker Cooling Lines Installed

Transformers were tested at full-rated electrical load with maximum ambient air conditions: worst case scenario. Thermocouple probes were placed on the outside surface of the transformers (prior to the potting operation). Test conditions were as follows:

- Ambient Air Temperature:

$52^{\circ} \mathrm{C}$

- 2-phase refrigerant temperature: $\quad 57^{\circ} \mathrm{C}$

- 2-phase refrigerant flow rate:

$20 \mathrm{gal} / \mathrm{hour}$

- Max transformer surface temperature: $85^{\circ} \mathrm{C}$ 
The toroid transformer outer surface temperature testing proved that the Parker cooling system maintained a much cooler transformer than the previously investigated air cooling method $\left(85^{\circ} \mathrm{C}\right.$ vs. $\left.117^{\circ} \mathrm{C}\right)$

The third method of cooling a transformer via flowing refrigerant through the live windings, a special transformer designed for this purpose was needed. One example of this type of transformer is a large 22 MVA 3 - phase transformer for a large medium voltage motor drive application. Each phase of the transformer coil consisted of a set of copper tubes that doubled as the electrical primary windings and a set of copper tubes that doubled as the electrical secondary windings. A picture of the coil can be seen below in Figure 7.

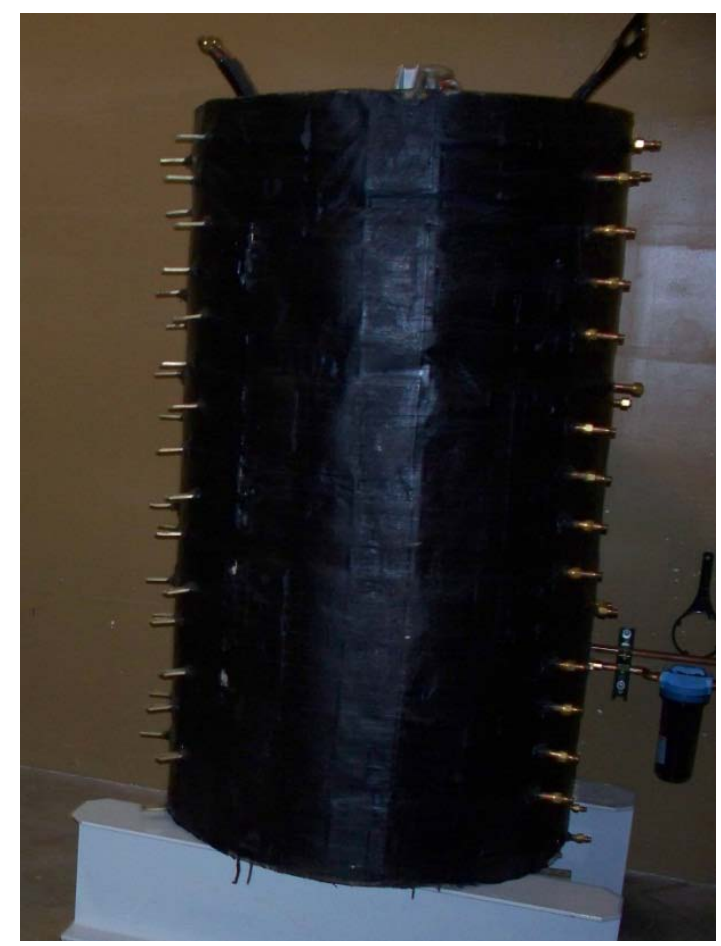

Figure 7 - Special Live Windings Transformer

Because the copper tubes double as the electrical windings, the copper tubes support a live voltage. Therefore, dielectric hose was needed to connect the windings to the rest of the cooling system. Liquid refrigerant could then be pumped into each winding as a liquid, where it then partially boiled as it absorbed heat and was then pumped to a condenser to reject that heat. For the sake of testing, low voltage was connected to each winding at very high current to heat up each winding in the same manner as an electric heating element. A picture of the test setup is shown in Figure 8. 


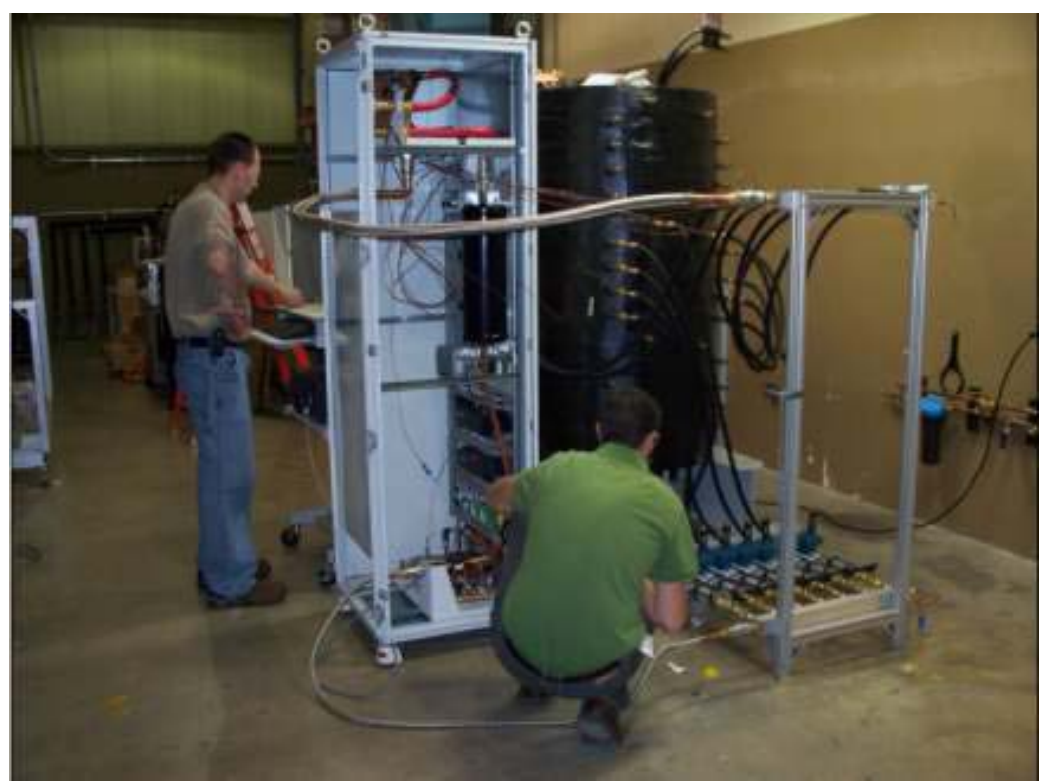

Figure 8 - Test Setup of Live Winding Transformer Parker Cooled System

Testing showed that under load, the windings remained essentially the same temperature as the refrigerant. This was expected since the surface area is so large and the individual heat loads relatively small, therefore a low heat flux. The greater concern to the customer was whether the very long lengths of copper coils combined with boiling refrigerant would create large slugs of vapor that could potential vapor lock or intermittently lose cooling to a transformer winding. Testing proved that this was not an issue and the refrigerant liquid and vapor were very well mixed at the exit of each coil, even near dry-out conditions.

Although this system provides the ultimate level of cooling efficiency, it requires a unique transformer design and additional design considerations due to isolating live windings from the rest of the cooling system. At the time of this report, Parker Precision Cooling Systems has not yet launched a production system with this method of transformer cooling.

\section{IGBT COOLING}

Part of a high-powered electrical inverter consists of IGBT's which provide the switching of high electrical currents at high frequencies. Several different IGBT modules were tested as part of various cooling systems.

One module tested was the Eupec FZ1200R17KF6CB2 module. It is a large IGBT module $130 \mathrm{~mm} \times 140$ $\mathrm{mm}$ in size with a rated current of $1200 \mathrm{amps}$. A picture of the Parker cold plate module and this testing can be seen below in Figures 9 and 10. 


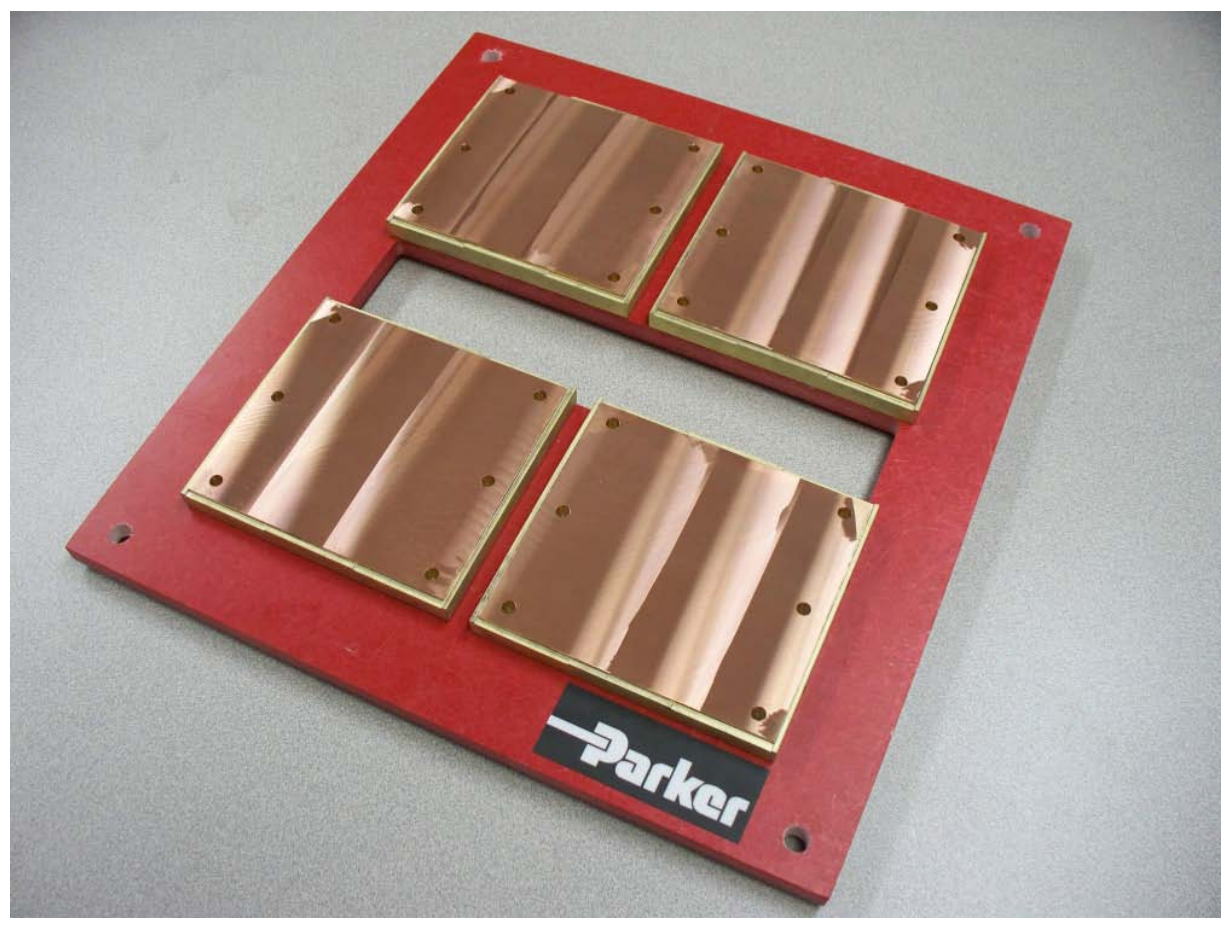

Figure 9 - Cold Plate Module Array

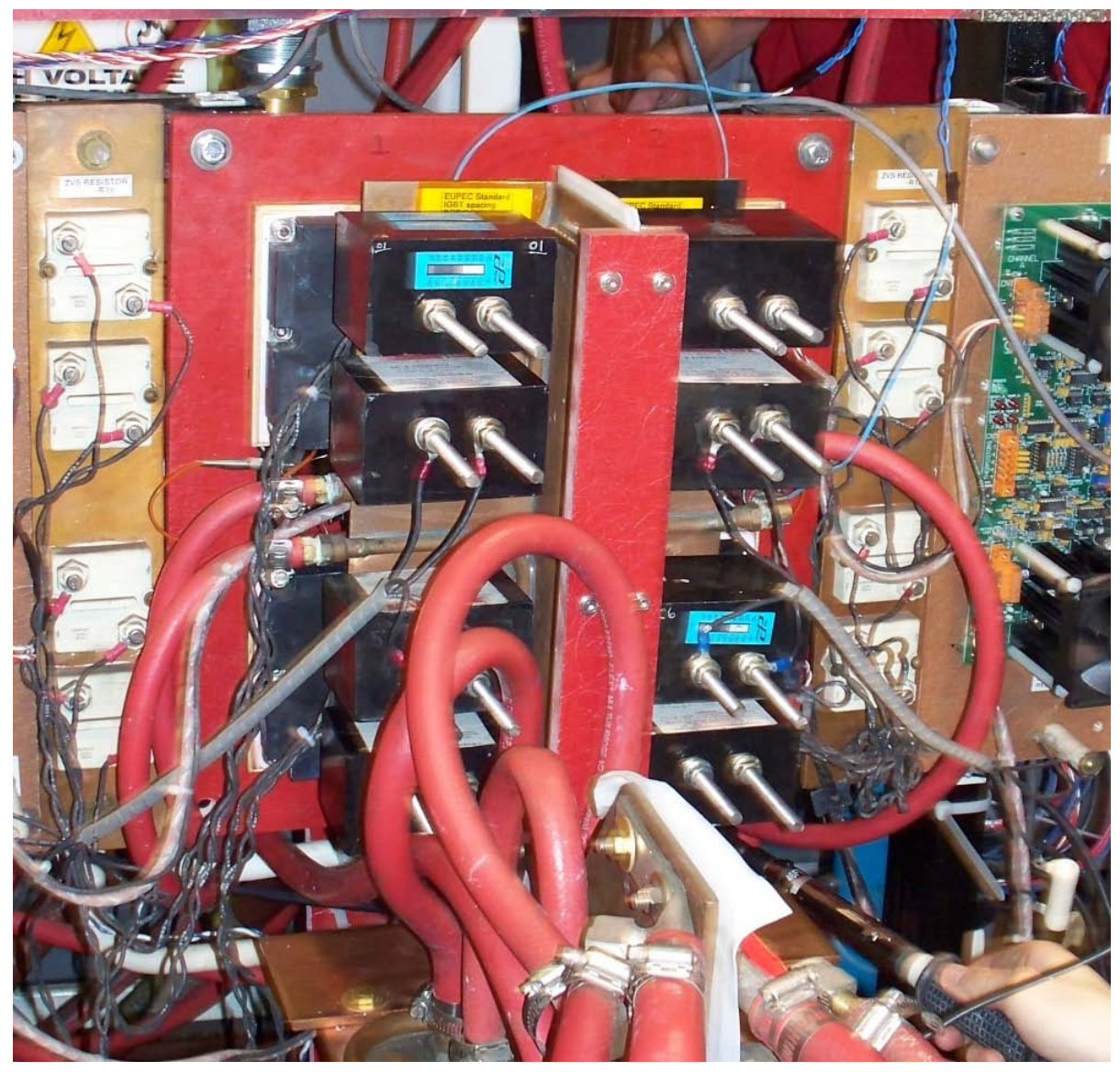

Figure 10 - Cold Plate Array Testing 
Testing was performed on the drive in order to determine the cold plate thermal resistance and compare that performance to the customer's current water cold plates. A screen capture from the testing is shared in Figure 11.

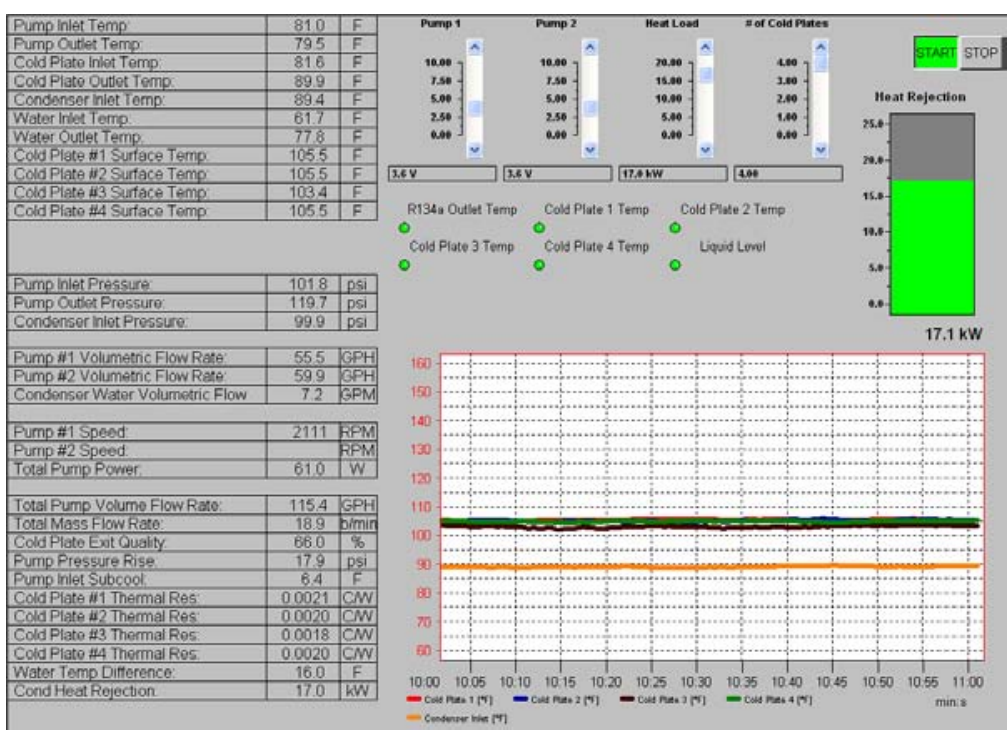

Figure 11 - Cold Plate Array Test Results Sample

Testing showed that the Parker cold plate thermal resistance was only $0.002{ }^{\circ} \mathrm{C} / \mathrm{W}$, approximately half of the customer's current water cold plate thermal resistance. The significant increase in performance allowed the customer to increase the power rating on their IGBT's and still keep them at a safe temperature.

Another IGBT tested was a base-plate-less module by Semikron called the SKiM93 module. The module is unique: the electronic circuit board is directly spring-loaded against the cold plate instead of being mounted to an intermediary copper plate, thus reducing the thermal resistance between the IGBT dies and the cooling fluid. A picture of the test setup can be seen below, Figure 12.

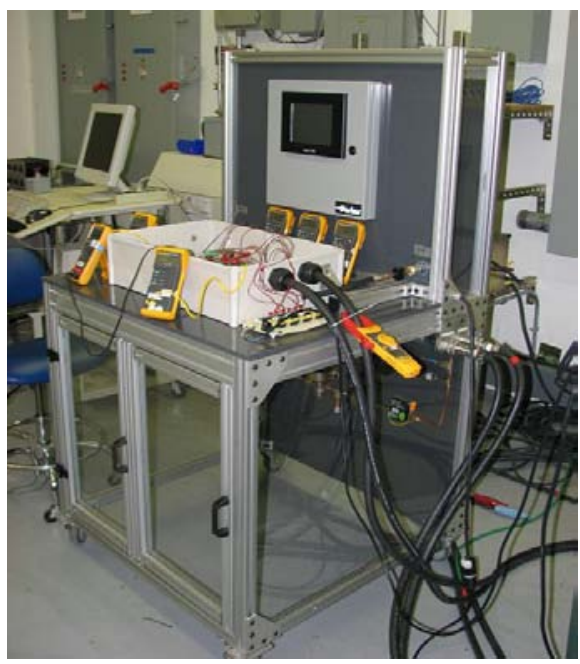

Figure 12 - Test Bench Setup for SKiM93 Module 
Thermal testing was performed with two-phase refrigerant cooling and compared with single-phase water cooling. The results can be seen below in Figure 13.

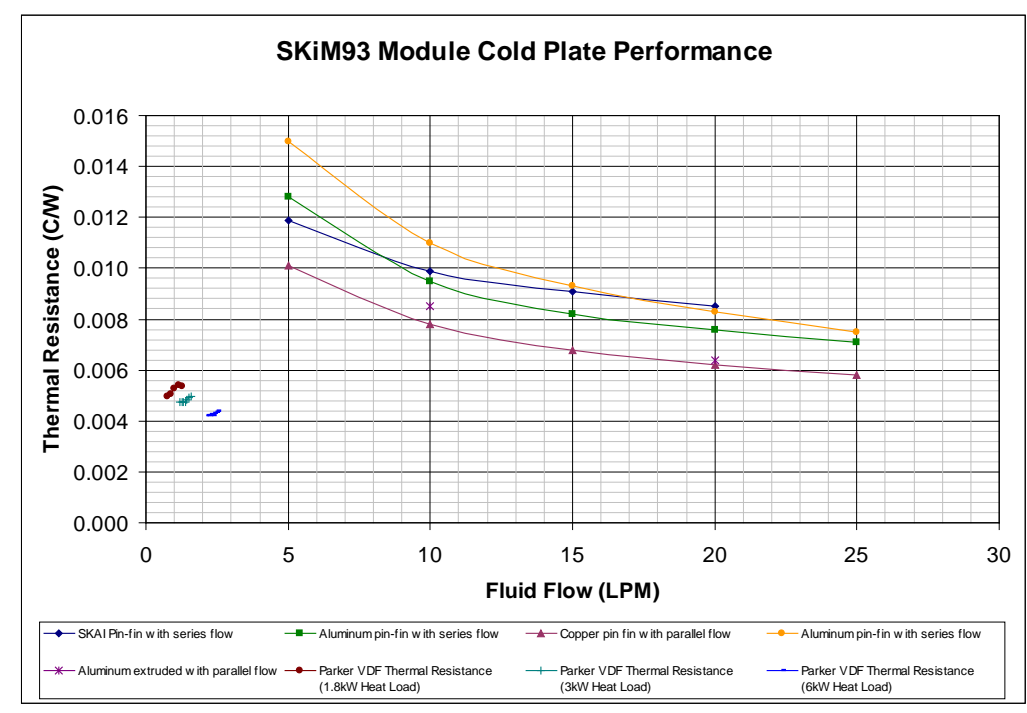

Figure 13 - Cold Plate Test Results

The various water cold plates tested were evaluated at 1,800 W heat loads and resulted in thermal resistances that gradually decreased with large increases in flow rate. The Parker two-phase cooling test results showed a significant decrease in thermal resistance at a significant decrease in flow rate. The testing was also performed at 3,000 W and 6,000 W. This was beyond the capabilities of the water cold plates. Testing showed that Parker's two-phase cooling resulted in 50\% lower thermal resistance at $80 \%$ less flow rate and $10 \%$ less thermal resistance at $96 \%$ less flow rate.

\section{BENEFITS ASSESSMENT}

The Parker cooling system benefits the power electronic community by providing a smaller and more powerful solution than air or water cooling solutions at significantly less pumping power.

Testing has proven that a two-phase cooling system needs much less fluid flow rate compared to similar water cooled solution. The flow rate reduction is on the order of 4 to 5 times less, and even greater in some cases. If you make the assumption that both systems are pumping against approximately the same restriction, this means that a two-phase solution is using 4 to 5 times less pumping power.

This means on a $1 \mathrm{MW}$ industrial drive with an efficiency of $95 \%$, there will be $50 \mathrm{~kW}$ of heat loss. The pumping power required to remove that heat with two-phase cooling is approximately $0.25 \mathrm{~kW}$. The pumping power required for an equivalent water cooled system is approximately $1.25 \mathrm{~kW}$. For a drive running continuously, this would result in $8760 \mathrm{~kW}$-hrs of energy savings annually.

In addition to energy savings, specific benefits are documented as followed:

Benefits of cooling transformers by passing refrigerant through the windings are as follows: 
- Winding temperature remains isothermal throughout the entire distance resulting in lower thermal stresses and higher efficiency

- Lower flow rates are required, resulting in smaller pumps, smaller hose sizes and lower energy consumption

- Fluid has higher dielectric strength than de-ionized water resulting in much shorter dielectric hose lengths

- A de-ionizing system is not needed to maintain the dielectric strength of the fluid

- If a leak should occur, the fluid will remain non-conductive, eliminating the risks of catastrophic damage

- Fluid vapor remains well mixed eliminating vapor lock issues

Benefits of cooling transformers using the potted cooling coil method are as follows:

- Potential to reduce size of transformer. Since most transformers are designed for air cooling, the higher heat transfer capacity of 2-phase refrigerant cooling would allow a reduction in wire size. This could reduce the size and weight of the transformer.

- Allows transformers to be packaged more tightly. Liquid cooling eliminates need for providing space for adequate air flow.

- Allows transformers to be packaged in air tight enclosures and be used on mobile / outdoor applications.

- Has minimal impact on transformer design. Off-the-shelf, conventional transformers can be utilized with this method of cooling.

- 2-phase refrigerant cooling in a potted coil tube can also be applied to other magnetic-based electrical components, such inductors (chokes, LC-filters).

Benefits of cooling IGBT's by passing refrigerant through them are as follows:

- Lower thermal resistance allowing for the devices to:

o Run at a lower temperature at the same fluid temperature

o Maintain a higher fluid temperature for the same device temperature

o Increase the power through the device and maintain the same device temperature

- Cold plate remains isothermal resulting in lower thermal stresses and longer life

- Lower flow rates are required, resulting in smaller pumps, smaller hose sizes and lower energy consumption

- If a leak should occur, the fluid will remain non-conductive, eliminating the risks of catastrophic damage

- No galvanic corrosion issues

- No maintenance required to the fluid

\section{COMMERCIALIZATION}

Several systems utilizing Parker's two phase cooling have been released into production during the time span of this DOE project and several more are still in the development cycle and are likely to launch to production in the very near future.

Power Generation - A switching mode power supply and transformer has been successfully cooled with the VDF technology with over (40) units in the field. The power supply is used to drive the power 
generation facility's electrostatic precipitator's which remove particulate from the exhaust air stream enabling them to meet EPA regulations.

Grid Energy Storage - Battery cooling was accomplished with the VDF technology and (6) complete containerized systems were shipped to a Midwest company for field testing in 2011. The VDF technology was also used on (32) units for power conversion systems used in grid energy storage applications also shipped in 2011.

Energy Efficient Heating - A customer is currently using the VDF technology to cool laser diodes being used in a unique heating application. Several units were shipped in 2010 and 2011 with preproduction planned for 2012, and full scale production to start in 2013.

Alternate Energy - A cooling system was designed for a flywheel energy storage customer to cool their power electronics and motor/generator. Product validation is currently underway.

\section{ACCOMPLISHMENTS}

The following describes the accomplishments of the DOE project in many market segments including wind energy, grid tie energy storage, heavy construction equipment, mining equipment, and medium voltage motor drives to name a few.

a. Designed a working lab system and pre-production system for cooling a motor/generator and power conversion system in a Fly-Wheel Energy Storage system.

b. Developed and shipped a Laser Diode Array cooling system for commercial applications.

c. Developed a lab system and several production units for a Switching Mode Power Supply used in Particulate Collection applications to help meet EPA requirements.

d. Developed Grid Energy Storage cooling systems in 40' ISO containers to maintain precise temperature control for lithium ion batteries.

e. Developed pre-production units for Power Conversion Stations that will be used in Battery Energy Storage Applications.

f. Began a project with a major Data Center manufacturer to cool their Servers.

g. Began a project to cool a grid tie inverter for a major Solar Energy company.

h. Demonstrated that transformers and inductors can be cooled adequately through using 2phase refrigerant flow through copper tubes wrapped around the peripheral surface of the device and potted in a thermally-conductive, epoxy compound.

i. Developed an Operations and Maintenance plan for the cooling systems.

\section{CONCLUSIONS}

The DOE funding from this grant enabled Parker Precision Cooling Business Unit accelerate its product development and testing for VDF cooling systems. The results of this accelerated development are shown in the preceding sections of this report outlining the three ways to cool transformers and the systems that were developed for IGBT cooling for converter and inverter applications. To fully validate these systems and show the value to potential customers, tests were conducted and showed that the two-phased cooling technology provided many benefits when compared to water and air cooling.

The two IGBT cooling tests that were conducted showed that a significant reduction in thermal resistance is possible with two-phased cooling. For the Eupec IGBT module, the thermal resistance for the cooling 
system was reduced to $0.002{ }^{\circ} \mathrm{C} / \mathrm{W}$ or about half of the existing cooling system. This reduction in thermal resistance directly translates into improved IGBT performance, which means fewer IGBTs are required in each system resulting in reduced energy consumption by the system and by the manufacturing process making the components. It can also result in a reduced footprint for the final system, leaving space for other components, or a reduced overall footprint. The Semikron SKiM93 module testing provided similar results that showed a roughly $50 \%$ decrease in thermal resistance from a water cooling system while also enabling an $80 \%$ reduction in fluid flow rates. This directly translates into less energy consumption by the cooling system and similar additional benefits as noted for the Eupec IGBT.

The transformer cooling projects showed that there are benefits of utilizing Parker's two-phased cooling technology by reducing the winding temperatures when compared to air cooled and water cooled units. To take full advantage of the unique benefits of the cooling system; however, it would be necessary to have a specially designed transformer that has internal passages for the refrigerant to flow. When this is done, the results include reduced transformer sizing (mass and dimensions), sealed outdoor rated transformers and reduced manufacturing cost (from materials usage and wasted) and reduced transportation costs (from reduced mass resulting in reduced fuel consumption). These benefits result in reduced energy usage from the manufacturing and transportation of these units and reduced GHG emissions when burning less fuel.

With the improved thermal performance of the electrical components used in these systems, customers are always finding new value in the technology. The value communicated by the customer is continuing to drive the commercialization of the two-phased cooling into the existing markets and new markets. The continued dialogue with customers has already resulted in improvements to the system design to make it more efficient and more effectively meet customer requirements. Those lessons are applied on the specific products for those customers and also on new products as they are developed by utilizing lessons learned from each project. Some of those lessons include development of a standard pump tray that can be easily swapped or used across multiple platforms and the use of redundant pumps when a very high level of system up time is required.

\section{RECOMMENDATIONS}

The VDF technology has clearly demonstrated that it has great potential to take on the greatest thermal management challenges and at the same time, be much more energy efficient than the competing technologies. It is recommended that this technology be further developed and commercialized by continued development efforts and expansion into additional applications and markets beyond those presented in this report. In support of the expansion into new applications, development on new or alternative components is needed. This includes new types of cold plates and couplings and expanding the materials utilized for system tubing. The continued effort to expand the components available for the systems will support the commercialization strategy of expanding to new markets by enabling the cooling systems to meet new and varied customer requirements. 
1. IEC 60529 e. In Ingress Protection (2.1 edition). International Electro-technical Commission. Retrieved from http://webstore.iec.ch/webstore/webstore.nsf/Artnum_PK/26766

2. Standard for Systems of Insulating Materials - General. In (2007). UL 1446 (6 edition). Retrieved from http://www.ul.com/global/eng/pages/solutions/standards/accessstandards/catalogofstanda rds/standard/?id=1446_6 